\title{
Ramifications of positive and negative contact experiences among remigrants from Russia to Finland
}

\section{Mähönen, Tuuli Anna}

2016-04

Mähönen , T A \& Jasinskaja-Lahti , I 2016 , ' Ramifications of positive and negative contact experiences among remigrants from Russia to Finland ', Cultural Diversity \& Ethnic Minority Psychology , vol. 22 , no. 2 , pp. 247-255 . https://doi.org/10.1037/cdp0000059

http://hdl.handle.net/10138/234348

https://doi.org/10.1037/cdp0000059

acceptedVersion

Downloaded from Helda, University of Helsinki institutional repository.

This is an electronic reprint of the original article.

This reprint may differ from the original in pagination and typographic detail.

Please cite the original version. 
Mähönen, T. A., \& Jasinskaja-Lahti, I. (2016). Ramifications of positive and negative contact experiences among remigrants from Russia to Finland. Cultural Diversity and Ethnic Minority Psychology, 22(2), 247.

Word count: 5842 (abstract 231 words)

SHORT TITLE: INTERGROUP CONTACT AND PERCEIVED THREATS AND GAINS

\section{Ramifications of positive and negative contact experiences among remigrants from Russia to Finland}

Tuuli Anna Mähönen* \& Inga Jasinskaja-Lahti

University of Helsinki, Finland

*Correspondending author: Open University, University of Helsinki, P.O. Box 53

(Fabianinkatu 32), FIN-00014 University of Helsinki (e-mail: tuulianna.mahonen@helsinki.fi; tel. +358 50448 8573).

\section{Abstract}

Objectives: This paper focuses on the effects of positive and negative contact with majority Finns on the outgroup attitudes of remigrants from Russia to Finland. We tested 1) whether negative contact leads to negative outgroup attitudes via perceived 
threats, and 2) whether positive contact leads to positive outgroup attitudes via perceived gains seen to result from contact with majority Finns. We also tested whether the effects of contact with majority members generalized to attitudes towards other immigrant groups living in Finland.

Methods: The study utilized two-wave longitudinal panel data on Ingrian-Finnish remigrants $\left(N_{\mathrm{T} 1}=136\right.$, mean age 46.4 years, $73 \%$ females; $N_{\mathrm{T} 2}=85$, mean age 49.3 years, $73 \%$ females).

Results: The results attested the effects of positive contact experiences on attitudes towards both majority and other minority group members, via perceived gains. As regards negative contact, it was associated with more negative attitudes towards the majority via perceived threats, but no evidence of secondary transfer effect on attitudes towards other immigrants was found.

Conclusions: The results highlight the importance of simultaneous examination of positive and negative contact. Especially positive contact and gains perceived to result from it can be powerful tools in promoting positive outgroup attitudes also among minority group members. The results also show the role of majority group members in defining inter-minority attitudes.

Key words: intergroup contact, perceived gains, perceived threats, outgroup attitudes, secondary transfer effect 


\section{Ramifications of positive and negative contact experiences among remigrants from Russia to Finland}

\section{Introduction}

To date, a considerable amount of research has attested the power of intergroup contact to reduce prejudice (Pettigrew, Tropp, Wagner, \& Christ, 2011; Pettigrew \& Tropp, 2006). However, as critically pointed out by Barlow and colleagues (2012), contact should not be seen as a synonym for positive contact or intergroup friendship, as often seems to be the case. Indeed, individuals are also exposed to negative intergroup encounters, and especially in the case of immigrants, negative contact includes not only unpleasant encounters but also different forms of unfair, discriminatory treatment (see, e.g., Jasinskaja-Lahti, Mähönen, \& Liebkind, 2012). Consequently, as the nature, subjective meaning and consequences of negative contact differ among members of advantaged and disadvantaged groups (e.g., Schmitt \& Branscombe, 2002), it should be studied and operationalized accordingly.

Moreover, previous research has focused more on the power of intergroup contact to affect the attitudes of majority group members towards minorities than vice versa, with studies on inter-minority contact being even rarer (but for exceptions, see Barlow, Louis, \& Terry, 2010; Bikmen, 2011; Mähönen, Ihalainen, \& Jasinskaja-Lahti, 2013; Phinney, Ferguson, \& Tate, 1997). Even though contact effects have been typically found to be weaker among minority than among majority group members, they exist (e.g., Pettigrew \& Tropp, 2006). Considering the constantly increasing cultural diversity in most societies today, the effects of both positive and negative contact on intergroup relations between minorities should also be addressed. 
In this paper, we focus on the effects of positive and negative contact with majority Finns on the attitudes of remigrants from Russia towards the majority and other immigrant groups living in Finland. We measure positive contact through experiences of pleasant, cooperative and non-superficial contact (cf. Allport, 1954). Negative contact, in turn, is operationalized as experiences of discriminatory and derogatory treatment (cf. Jasinskaja-Lahti et al., 2012; Stephan et al., 2002). We test two indirect paths: one from negative contact experiences to negative outgroup attitudes via perceived threats, and another from positive contact experiences to positive outgroup attitudes via perceived gains. More specifically, in line with previous research on perceived threats (Stephan \& Stephan, 2000; Stephan, Renfro, \& Davis, 2008) and gains (Mähönen, Jasinskaja-Lahti, Liebkind, \& Finell, 2011), realistic threats and gains are seen in this paper to be related to economic or material well-being of a person and his/her ingroup, while symbolic threats and gains are seen to involve cultural way of life and worldview. Besides complementing previous research with the notion of perceived intergroup gains, we also aim to contribute to recent developments of contact hypothesis with the assessment of both positive and negative contact (Pettigrew et al., 2011; Barlow et al., 2012) and with the testing of secondary transfer effect of contact (e.g., Pettigrew, 2009; Tausch et al., 2010; Vezzali \& Giovannini, 2012) among minority group members. We argue that acknowledging the perceived consequences of intergroup interaction (i.e., perceived threats and gains) helps us understand better the attitudinal ramifications of positive and negative contact. 
Previous studies combining Allport's (1954) contact hypothesis with Stephan and colleagues' intergroup threat theory (Stephan \& Stephan, 2000; Stephan et al., 2008) have shown that perceived threats mediate the relationship between contact and outgroup attitudes (e.g., Stephan, Diaz-Loving, \& Duran, 2000). However, the results have been partly mixed depending of the type of threat and intergroup context studied (see Tausch, Tam, Hewstone, Kenworthy, \& Cairns, 2007; González, Verkuyten, Weesie, \& Poppe, 2008). In this line of research, the focus has been on the power of (positive) contact to reduce perceived threats, and consequently, also prejudice towards outgroups. However, while research has found the effect of positive contact on positive attitudes to be due to the decrease in "negative" mediators (such as perceived threats), there is less research on "positive" mediators, i.e., factors enhanced by positive intergroup interaction (but see, e.g., Brown \& Hewstone, 2005; Pettigrew, 1998). Thus, besides threat accounts, also the examination of the more positive mediators of contact effects is crucial: there has been a call for a shift from research on prejudice reduction to research on motivations and processes underlying positive intergroup relations (e.g., Tropp \& Mallett, 2011).

In a previous study on the perceived importance of contact among majority adolescents (Mähönen et al., 2011), the distinction between realistic and symbolic threats (Stephan \& Stephan, 2000; Stephan et al., 2008) was employed to study perceived realistic and symbolic gains; that is, material and cultural gains perceived to result from intergroup contact. Then, perceived realistic and symbolic gains were found to be associated with more positive implicit and explicit outgroup attitudes, respectively, even when controlling for the quality and quantity of intergroup contact. However, to our knowledge there are no previous studies elaborating on the 
conceptual difference between perceived threats and gains on outgroup attitudes, nor on the simultaneous mediating effects these might have.

In this study, we examine the ramifications of positive and negative contact among remigrants and suggest that perceived gains and threats serve as their respective mediators. As positive and negative contact experiences have been suggested to have distinct attitudinal repercussions (Barlow et al., 2012), we also expect their mediators to differ. Based on studies showing the mediating effect of perceived threats on contact-attitude association, we expect negative contact to result in higher levels of perceived threat, further reflected in more negative outgroup attitudes.

Both perceived threats and gains can be regarded as anticipated consequences of intergroup contact (cf. Mähönen et al., 2011). They can also be seen from the viewpoint of instrumental intergroup relations: there are things to gain or lose when engaging in intergroup interaction (cf. Esses, Jackson, Dovidio, \& Hodson, 2005). Thus, given the scarcity of previous studies, we base our hypothesis related to the role of perceived intergroup gains on threat literature discussed above. We expect the effect of remigrants' positive contact experiences on more positive outgroup attitudes to be mediated by gains perceived to result from intergroup contact with the majority group.

\section{The secondary transfer effect}

There is a small but growing body of literature showing both crosssectionally (Tausch et al., 2010; Vezzali \& Giovannini, 2012), longitudinally (Pettigrew, 2009; Eller \& Abrams 2004; van Laar, Levin, Sinclair, \& Sidanius, 2005; Tausch et al., 2010) and experimentally (Harwood, Paolini, Joyce, Rubin, \& Arroyo, 2011) that the effects of contact with primary outgroups can be generalized to secondary 
(unrelated) outgroups. In addition, recent research suggests that intergroup contact can increase appreciation of diversity: support for multiculturalism has been found to mediate the effects of contact on attitudes towards different outgroups (Lolliot, 2013). Thus, it may be the case that positive contact experiences make the individual see the good that can results from intergroup interaction and cultural diversity, which is further reflected in more positive attitudes towards outgroups - both primary (i.e., group involved in the intergroup interaction) and secondary (i.e., unrelated outgroups).

However, to our knowledge, there are only three existing studies on the so-called secondary transfer effect of contact (STE; Pettigrew, 2009) between minority group members. The first study was conducted by Lebedeva and Tatarko (2005) in Russia among eight different ethnic minority and internal migrant groups. In this study, experiences of discrimination increased ethnic intolerance and religious differentiation among minority group members. However, the source of discrimination was not specified, thus making it impossible to make strong claims about STEs. The second study concerned cross-group friendships among White, Black and Coloured South Africans (Swart, 2008, as cited in Lolliot et al., 2013, p. 100). It was found that crossgroup friendships between Black and White South Africans predicted less prejudiced attitudes of Black minority group members towards the White majority group, but not towards Coloured minority group members. The most recent study by Bowman and Griffin (2012) conducted in the USA reported several positive STEs among Asian, Black and Hispanic college students when predicting their attitudes towards each other and White students. However, in some cases no statistically significant STEs were found, or the effects were negative. 
Regarding the mediators of STE, previous studies have focused on attitudes towards the primary outgroup (related to the so-called attitude generalization hypothesis of STE), ingroup identification, social identity complexity and multiculturalism (related to the so-called deprovincialization hypothesis of STE), and empathy towards primary and secondary outgroups (for a review of mediators, see Lolliot et al., 2013). However, we know of no previous STE studies distinguishing between positive and negative contact and testing for mediating effects of perceived gains and threats. Based on the idea that contact experiences are related to the valuing of diversity (see Lolliot, 2013; Tropp \& Bianchi, 2006), we argue that both positive and negative contact experiences make people assess not only the primary outgroup as such, but also the value of engaging in contact with outgroups in general. Thus, we propose that negative and positive contact experiences with the majority predict threats and gains perceived to result from intergroup contact, and they in turn are reflected in attitudes towards both the majority and other immigrant groups.

Research questions and hypotheses

First, to complement previous research on positive and negative contact and research on the mediators of contact effects, we ask whether there are indirect paths from remigrants' positive contact experiences with majority Finns to positive attitudes towards them via perceived gains, and from negative contact experiences to negative attitudes towards majority Finns via perceived threats. 
H1. We expect positive contact with majority Finns to be associated with higher perceived gains, which in turn are expected to be associated with more positive attitudes towards majority Finns.

$\mathrm{H} 2$. We expect negative contact to be associated with higher perceived threats, which in turn are expected to be associated with more negative attitudes towards majority Finns.

Given the scarcity of previous research, there is a need to verify whether positive contact only results in more perceived gains and not in fewer perceived threats, and whether negative contact only results in more perceived threats and not in fewer perceived gains. That is why we also check for the competing effects of positive contact on outgroup attitudes via perceived threats, and the effects of negative contact on outgroup attitudes via perceived gains, as well as for direct effects of contact experiences on attitudes.

Second, to complement previous research on secondary transfer effects of contact, we also ask whether the effects of intergroup contact with majority Finns are generalized towards other immigrants living in Finland via perceived threats and gains perceived to result from these contact experiences. Two primary hypotheses ( $\mathrm{H} 3 \mathrm{a}$ and $\mathrm{H} 4 \mathrm{a}$, see below) are formulated suggesting a positive STE of positive contact and a negative STE of negative contact respectively. However, it is possible to formulate also alternative hypotheses related to STEs. Namely, perceived gains resulting from contact with the majority may also be reflected in more negative attitudes towards other immigrants, if these gains increase perceived permeability of group boundaries and identification with the majority and make the remigrants studied distance themselves 
from other minority groups (for related discussion, see Mähönen \& Jasinskaja-Lahti, 2012). It is also possible that threat perceptions evoked by contact with majority group members are reflected in more positive attitudes towards other immigrants, if they are seen as allies against the majority (for a related discussion, see Bowman \& Griffin, 2012; Tausch et al., 2010). Considering the lack of previous research, we test also two alternative hypotheses ( $\mathrm{H} 3 \mathrm{~b}$ and $\mathrm{H} 4 \mathrm{~b})$, as outlined below.

H3a. We expect positive contact with majority Finns at T1 to be associated with more positive attitudes towards other immigrants at T2 via perceived gains at T2. $\mathrm{H} 3 \mathrm{~b}$. As an alternative hypothesis, we test if positive contact with majority Finns at T1 is associated with more negative attitudes towards other immigrants at $\mathrm{T} 2$ via perceived gains at $\mathrm{T} 2$.

H4a. We expect negative contact with majority Finns at T1 to be associated with more negative attitudes towards other immigrants at $T 2$ via perceived threats at $T 2$.

H4b. As an alternative hypothesis, we test if negative contact with majority Finns at T1 is associated with more positive attitudes towards other immigrants at $\mathrm{T} 2$ via perceived threats at $\mathrm{T} 2$.

Intergroup context studied

Finland is characterized by a low proportion of immigrant population (ca. $5 \%$ of the total population; Statistics Finland, 2013) and by a high proportion of Russian-speakers compared to other non-native language groups (i.e. other than Finnish, Swedish or Sami). In fact, $23 \%$ of all non-native language speakers in Finland speak 
Russian (Statistics Finland, 2013). Soon after the collapse of the Soviet Union, Russian nationals of Finnish descent and their family members gained the right to remigrate to Finland, which counts for much of Finland's rapidly increasing Russian-speaking population. Most of these remigrants represent the so-called Ingrian-Finns, the descendants of Finns emigrated from Finland to Russia between the 17th and the beginning of the 20th century. The participants of this study represent a sample of Ingrian-Finnish remigrants living in Finland.

The wars between the Soviet Union and Finland during WWII still cast a shadow on intergroup relations between the Finnish majority and the Russian-speaking minority in Finland. While the status of Ingrian-Finns is relatively higher than that of other immigrants from Russia to Finland (Liebkind et al., 2004), despite the cultural similarities, the Finnishness of Ingrian-Finns is often questioned by majority Finns (e.g., Davydova \& Heikkinen, 2004; Varjonen, Arnold, \& Jasinskaja-Lahti, 2013). Moreover, due to their relative monolingualism in Russian, Ingrian-Finns are often mixed up with Russians by the majority. As a result, regardless of their ethnic background, all Russianspeaking immigrants are often victims of ethnic discrimination and prejudice in Finland and belong to the least welcomed immigrant groups along with Somalis and Arabs (e.g., Jaakkola, 2005; Jasinskaja-Lahti, Liebkind, \& Perhoniemi, 2006). Therefore this context provides a natural setting in which to study the ramifications of not only positive, but also negative contact.

\section{Method}

Participants and procedure 
This study was based on the final two waves of the four-wave INPRES/LADA research program following the migration process of Ingrian-Finns starting from the pre-migration stage (for information about the first three waves, see Jasinskaja-Lahti et al., 2012). We thus focused here on the later stages of the migration process, when participants were not newcomers anymore, and already had varying experiences of intergroup encounters with both majority Finns and other immigrant groups living in Finland. Also, at this stage, we were able to ask the respondents to evaluate the threats and gains that were perceived to result from intergroup contact with Finns. For the sake of clarity, the two time points included in the present study are from now on referred to as $\mathrm{T} 1$ and $\mathrm{T} 2$, instead of $\mathrm{T} 3$ and $\mathrm{T} 4$.

The T1 data was collected between November 2010 and October 2011, and at that stage participants had been living in Finland on average for almost two years ( $M=22$ months, $S D 4$ months, ranging from 13 to 28 months). The T2 data of this study, in turn, were collected between September 2012 and January 2013, thus ca. 1-2 years after the previous wave. The variation in the length of residence is due to the personal migration schedules of the participants: the baseline data of the INPRES project were collected in the pre-migration stage, and in order to get enough participants for the first follow-up, we had to wait for enough participants to migrate. After that, each data collection was aimed to be completed ca. one year after the previous one, but the initial variation in the length of residence is reflected in all the data sets. In addition, there was some delay due to the sending of reminder letters which were needed to get as many participants as possible. Besides sending the reminders, the remigrants were motivated to continue participating in the project by stressing the importance of the 
information and the uniqueness of the data gained. Also, small gifts costing less than 10 euros were included with the questionnaires.

Of the original pre-migration respondents $(N=224), 61 \%$ participated in $\mathrm{T} 1$ of the present study and $38 \%$ in $\mathrm{T} 2$ of the present study. In order to examine possible selection bias due to sample attrition, we compared the relevant demographic factors (gender, age, marital status, socioeconomic status, employment status, Finnish language proficiency, health status), as well outgroup attitudes and contact experiences between participants who did or did not participate also in the T2 data collection of the present study. No statistically significant differences were found.

The T1 data of the present study consists of 136 Ingrian-Finnish participants, representing $82 \%$ of all the baseline participants remigrated to Finland by December 2010 and $86 \%$ of the participants of the previous follow-up. The mean age of the participants was 46.4 years $(S D=14.1)$, and most participants were females $(73 \%)$. As regards subjective SES, when asked to evaluate the current economic situation of oneself / one's family on a scale from 1 ("we have enough money for our own needs and more") to 5 ("we need to reduce all consumption and we cannot survive with our own income"), the mean was $3.35(S D=.88)$. The T2 data, in turn, consists of 85 participants, and it includes $63 \%$ of the participants of the previous wave and $76 \%$ of the participants who gave their permission to contact them for this follow-up. This time, their mean age was 49.3 years $(S D=14.0)$, and again most participants were females (73\%). As regards subjective SES assessed with the scale reported above, the mean was $3.06(S D=.88)$.

Participation in all stages of the project was voluntary, and written consent for collecting follow-up data was obtained from each participant. The participants were 
reached through contact information gained from the Finnish National Population Register. As a whole, the collection, analysis and storage of data was conducted in line with the recommendations of the Finnish Advisory board on Research Integrity.

\section{Measures}

Participants answered the questionnaires in Russian. The measures used were back-translated from previously reported English versions to Russian by official translators and native Russian-speakers. Except for the measure of perceived gains, all the measures were adapted from scales that have been previously used also in research on immigration. The measure of perceived gains, in turn, was developed on the theorization of Stephan and colleagues (2008) on perceived threats.

Positive contact experiences (T1). Based on the dimensions of optimal contact (Allport, 1954; Islam \& Hewstone, 1993), participants evaluated the pleasantness, cooperativeness and superficiality (reversed) of their contact experiences with five groups of majority Finns that they had met in public and private spheres: colleagues in courses or at work, neighbours, close friends, teachers/employers, and authorities. All 15 items were assessed on a five-point scale from 1 (not at all) to 5 (very much), with higher scores denoting more positive contact experiences. The reliability of the scale was $\alpha=.70$.

Negative contact experiences (T1). Two items were used to measure negative contact experiences with majority Finns. They were adapted from the perceived discrimination scale of the ICSEY study (reported in Berry et al., 2006) and are in line with the measurement of negative contact in the study of Stephan et al. (2002). The items included: "Native Finns have teased or insulted me, because I am 
Ingrian-Finnish", and "Native Finns have threatened or attacked me, because I am Ingrian-Finnish". The participants assessed the items on a scale from 1 (strongly disagree) to 5 (strongly agree), with higher scores denoting higher levels of negative contact experiences. The Spearman-Brown reliability coefficient was $r=.74$.

Perceived threats and gains (T2). As an instruction to the measures on perceived threats and gains, we asked participants to "think about the negative and the positive consequences of the interaction between majority Finns and Russian immigrants from your own and your group's perspective". In the questionnaire it was made clear that by ingroup we meant the Ingrian-Finns living in Finland. Based on Stephan and colleagues' (2008) updated theorisation on intergroup threat, our four-item threat measure consisted of two items tapping personal and group-level realistic threats and two items tapping personal and group-level symbolic threats. Related to realistic threats, the participants were asked to evaluate on a five-point scale ( $1=$ strongly disagree to $5=$ strongly agree) whether Finns threaten the material well-being of 1 ) migrants from Russia and 2) of the participant and his/her family. With regard to symbolic threats, the participants were asked to evaluate whether Finns threaten 1) the culture of migrants from Russia and 2) the participant's or his/her family's Russian way of life. In a similar vein, we used two items to measure personal and group-level realistic gains and two items tapping personal and group-level symbolic gains. The reliability of the scale measuring perceived realistic and symbolic threats was $\alpha=.89$.

As regards realistic gains, the participants evaluated whether contact with Finns improves 1) the material well-being of migrants from Russia, and 2) of the participant and his/her family. Related to symbolic gains, the participants evaluated whether contact with Finns enriches 1) the culture of migrants from Russia and 2) the 
participant's or his/her family's Russian way of life. The participants rated all threat and gain items on a five-point scale from 1 (strongly disagree) to 5 (strongly agree), with higher scores denoting higher level of perceived threats/gains. The reliability of the scale measuring perceived realistic and symbolic gains was $\alpha=.91$.

Outgroup attitudes (T1, T2). Feeling thermometers previously used in contact and STE studies (see, e.g., Harwood et al., 2011; Tausch et al., 2010) were used to measure outgroup attitudes. The participants indicated on a scale from 0 to 100 , how cold/warm feelings they had towards 1) majority Finns and 2) other immigrant groups than immigrants from Russia living in Finland.

\section{Data analysis}

The hypotheses were tested with path analysis: due to the limited sample size we used observed instead of latent indicators for all variables in the model. The modeling was conducted with maximum likelihood estimation and regression imputation of data, using Amos 18.0 (Arbuckle, 2010). The initial hypothesized model presented in Figure 2 included four input exogenous variables measured at T1, two mediating endogenous variables measured at T2 and two dependent endogenous variables measured at T2. To test the hypothesized indirect effects of positive contact on outgroup attitudes via perceived gains and of negative contact via perceived threats, we also estimated paths from positive contact to perceived threats and from negative contact to perceived gains. In addition to the hypothesized paths, the covariances between the disturbances of the endogenous variables were estimated (Preacher \& Hayes, 2008), and the exogenous variables were set to correlate. The hypothesized 
indirect effects were tested with bootstrapping method with 5000 resamples (see Hayes, 2009; Preacher \& Hayes, 2008).

Figure 1 about here

\section{Results}

\section{Descriptive statistics}

The bivariate correlations, means and standard deviations of the variables studied are presented in Table 1. On average, the participants reported quite high levels of positive contact experiences and low levels of negative contact experiences. As regards the sample-level mean differences between $\mathrm{T} 1$ and $\mathrm{T} 2$ measurements, remigrants' attitudes towards majority Finns were more positive than their attitudes towards other immigrant groups both in $\mathrm{T} 1(t(83)=6.87, p<.001)$ and $\mathrm{T} 2(t(82)=7.48$, $p<.001)$. However, there were no statistically significant mean differences between the two time points in attitudes towards majority Finns $(t(83)=1.73, p=.087)$, or in attitudes towards other immigrants $(t(82)=1.45, p=.152)$. As regards the proposed mediators, the participants perceived more gains than threats to result from intergroup contact with majority Finns $(t(83)=-9.29, p<.001)$. All predictor variables correlated statistically significantly in expected directions with attitudes towards majority Finns at T2. However, the only predictor significantly and positively associated with attitudes towards other immigrants at $\mathrm{T} 2$ was perceived gains.

Table 1 about here 


\section{Testing of the hypotheses}

The hypothesised model ${ }^{1}$ presented in Figure 1 fitted the data adequately: $\chi^{2}(10, N=$ $85)=12.84, p=.233, \mathrm{RMSEA}=.036$, pclose $=.623(\mathrm{CI} 90 \%: .000-.085), \mathrm{NFI}=.970$, $\mathrm{CFI}=.993$. The preliminary results of the path analysis suggested that there was a statistically significant positive path from positive contact at $\mathrm{T} 1$ to more perceived gains at T2 $(\beta=.33, p<.001)$ and further from perceived gains to more positive attitudes towards both outgroups at T2 $(\beta=.27, p<.001$ for attitudes towards Finns and $\beta=.22$, $p<.001$ for attitudes towards other immigrants). Also, as hypothesized, negative contact at T1 was associated with more perceived threats at T2 $(\beta=.30, p<.001)$, which in turn were significantly associated with more negative attitudes towards Finns $(\beta=-.20, p<.001)$, but not towards other immigrants $(\beta=.02, p=.698)$ at $\mathrm{T} 2$. Importantly, there were no statistically significant associations between positive contact at $\mathrm{T} 1$ and perceived threats at $\mathrm{T} 2(\beta=-.10, p=.116)$, or between negative contact at $\mathrm{T} 1$ and perceived gains at $\mathrm{T} 2(\beta=-.01, p=.938)-$ thus speaking for the distinct ramifications of positive and negative contact experiences.

Given the limited sample size, we decided to test for indirect effects with a model including only the statistically significant hypothesized associations found. This model was not statistically significantly better than the one including non-significant associations $\left(\chi^{2}\right.$ diff. $(3, N=85)=2.65 \mathrm{~ns}$.), but we turned to the more parsimonius one

\footnotetext{
${ }^{1}$ In addition, we ran a model including direct paths from $\mathrm{T} 1$ positive and negative contact to $\mathrm{T} 2$ attitudes towards both outgroups $\left(\chi^{2}(6, N=85)=3.68, p=.720\right)$. There was no statistically significant difference between the models including or not including direct associations $\left(\chi^{2}\right.$ diff. $(4, N=85)=9.16 \mathrm{~ns}$.), but given the small sample size, we decided to leave the direct associations out from the final model, as none of these associations were even close to statistical significance and suggested the possibility of indirect effects. We also ran a model testing a reverse causal order from $\mathrm{T} 1$ attitudes to $\mathrm{T} 2$ contact, even though the measure of positive contact at T2 (i.e., outgroup friendships) was different from T1. All the paths from attitudes to mediators and from mediators to positive and negative contact were non-significant, and the model fit was unacceptable $\left(\chi^{2}(10, N=85)=43.01, p=.000\right)$.
} 
as it also fitted the data well $\left(\chi^{2}(13, N=85)=15.49, p=.278\right.$, RMSEA $=.029$, pclose $=.719(\mathrm{CI} 90 \%: .000-.076), \mathrm{NFI}=.964, \mathrm{CFI}=.994)$. As can be seen from Figure 2 presenting the results of the final model, the pattern of the results remained similar. To test for the indirect effects of $\mathrm{T} 1$ positive and negative contact on T2 outgroup attitudes via perceived threats and gains, we conducted bootstrapping analyses using 5000 resamples with $95 \%$ confidence interval (bias corrected percentile method). The estimate for the total indirect effect of positive contact on attitudes towards majority Finns equalled $1.45, p=.002$ (95\% CI .55 to 2.59$)$, and the estimate for the total indirect effect of negative contact on attitudes towards majority Finns equalled $-1.64, p=.017$ ( $95 \%$ CI -3.57 to -.21 ). The estimate for the total indirect effect of positive contact on attitudes towards other immigrants equalled $1.72(S E=.51), p=.010(95 \% \mathrm{CI} .43$ to $3.34)$.

In sum, our hypotheses $\mathrm{H} 1$ and $\mathrm{H} 2$ on the effects of positive and negative contact on attitudes towards majority Finns gained support, as well as our hypothesis H3a related to the STE of positive contact with majority Finns on attitudes towards other immigrants. However, we found no support for H4a related to the STE of negative contact on attitudes towards other immigrants. Alternative, secondary hypotheses $\mathrm{H} 3 \mathrm{~b}$ and $\mathrm{H} 4 \mathrm{~b}$ gained no support.

Insert Figure 3 about here

\section{Discussion}

This study was the first to show the distinct paths from remigrants' negative and positive contact experiences to attitudes towards outgroups via perceived 
threats and gains, respectively. The results complement previous research on the mediating effect of perceived threats on contact-attitude association (e.g., Stephan et al., 2000; Tausch et al., 2007; González et al., 2008) by showing the value of incorporating perceived intergroup gains in the analysis of positive intergroup relations (cf., Jonas, 2009; Tropp \& Mallett, 2011; Mähönen et al., 2011). In fact, while negative contact was reflected in perceived threats and further in more negative attitudes towards the majority, positive contact experiences was reflected in perceived gains and further in more positive attitudes towards the majority and other immigrant groups. This finding among remigrants thus extends the existing literature on secondary transfer effects between minority groups that has this far utilized student and national minority samples (Bowman \& Griffin, 2012; Lebedeva \& Tatarko, 2005; Swart, 2008, as cited in Lolliot et al., 2013, p. 100).

As far as the relative importance of positive and negative contact is concerned, the present studies attested the effects of them both on outgroup attitudes. However, with regard to the mediators, the results highlighted especially the role of perceived gains. More research is still needed to determine the interrelationships between the two types of contact and perceived threats and gains. For example, it might be that negative contact evokes a threat to one's security (see, e.g. Riek, Mania, \& Gaertner, 2006) which could work as a more potent mediator of negative contact than other forms of threats. However, in this study, security threats were not measured, as they could have potentially overlapped with the measure of negative contact we used. It might also be possible that the nonconfirmation of our hypothesis related to the indirect effect of negative contact on attitudes towards other immigrant groups is due that perceived threats are related to a specific outgroup or to a specific situation, while 
perceived gains are more generally related to valuing diversity. This idea is supported by previous theorization on negative and positive emotions: while negative emotions are adaptive in specific threatening situations, positive emotions broaden people's momentary perspectives also to other situations, thus promoting positive social relationships (for discussion, see Fredrickson, 2001). However, these tentative ideas cannot be confirmed with the present data.

As regards limitations and future directions, first, we wish to point out that the measures of positive and negative contact represented quite extreme ends of the positive-negative continuum, and due to the limited sample size and concise measures of threats and gains used, we were not able to distinguish between realistic and symbolic or personal and group-level threats and gains (cf. Stephan et al., 2008). Thus, we urge future research to use a variety of measures of negative and positive contact and look at the possibly different roles of the different types of threats and gains (see Stephan et al., 2008). Second, as we would have optimally needed three waves of data to test the proposed mediation hypotheses, the causal paths suggested could not be fully confirmed. Consequently, further experimental and longitudinal research is needed to test the proposed model. Third, perceived threats and gains were could not be controlled for in $\mathrm{T} 1$, as they were measured only in the later stage of the migration process. This strategy was chosen, because the assessment of the consequences of intergroup contact for oneself and the ingroup is not only easier, but also based on more frequent actual experiences when the immigrant has lived a bit longer in the new environment. Moreover, the optimal testing of secondary transfer effects would have required a control for T1 contacts with the secondary outgroup (cf., van Laar et al., 2005; Tausch et al., 2010). However, given the participants' relative monolingualism in Russian and 
limited social networks right after migration to Finland ${ }^{2}$, we made a decision not to include measures of inter-minority contacts before the final follow-up data collection. Nevertheless, we were able to control for attitudes towards both outgroups at $\mathrm{T} 1$, so that the effects of contact are calibrated by, but independent from, the effect of the initial level of outgroup attitudes measured at T1. In future longitudinal studies, positive and negative contact experiences, their mediators as well as outgroup attitudes should optimally be assessed in all three time points.

Fourth, we assessed attitudes towards a rather undefined outgroup of "other than Russian immigrant groups living in Finland", similarly to many previous studies on "attitudes towards immigrants" conducted among majority group members (e.g., Vezzali \& Giovannini, 2012). Given the inconsistent previous findings of STEs between different minority groups (Bowman \& Griffin, 2012), it is worth studying inter-minority relations also between specific groups in the future. Finally, as the immigrant group studied is culturally and ethnically close to the majority, its' status somewhat differs from that of other immigrant groups in Finnish society (see Liebkind et al., 2004). Thus, future studies should examine the roles of perceived threats and gains also among other immigrant groups to test the generalizability of our findings. However, our model was derived from previous theorizations tested also among ethnic minorities. Thus, we believe that perceived threats and gains are relevant mediators of contact also among other immigrant groups than the remigrants studied here.

\footnotetext{
${ }^{2}$ In our ongoing SINI research project on inter-minority relations in Finland (unpublished data, available from authors on request), we asked how often Russian $(N=246)$ and Estonian $(N=215)$ immigrants had brief interactions with Estonian/Russian and Somalian immigrants. On a scale from 1 (never) to 5 (every day), the means were quite low: Russian immigrants' contact with Estonian $(M=2.88, S D=1.21)$ and Somalian immigrants $(M=2.05, S D=1.16)$; Estonian immigrants' contact with Russian $(M=2.55, S D=$ $1.21)$ and Somalian immigrants $(M=1.60, S D=.91)$.
} 
We end with our message to the field. A number of previous studies have concluded that the potential of intergroup contact to reduce prejudice among minority group members is limited (Binder et al., 2009; Tropp \& Pettigrew, 2005). However, based on the results of this study, positive contact can be a powerful tool to promote positive outgroup attitudes also among immigrants (see also Jasinskaja-Lahti, Mähönen \& Liebkind, 2011). Recent research has also reported some alarming evidence about the harmful effects of negative contact on outgroup attitudes (Barlow et al., 2012). Nevertheless, the present results showed that besides focusing on the reduction of discrimination and perceived threats, there is at least as strong a reason to focus on the promotion of positive intergroup interaction and gains resulting from it. Pleasant intergroup experiences can help people see the value of diversity and intergroup interactions, and these positive effects can also spill over to attitudes towards other outgroups.

\section{Acknowledgements}

This research was supported by the Academy of Finland research grants No 123297 and No 257079 (INPRES and LADA projects). We thank Tamara Kinunen, Michail Vinokurov, Anu Yijälä, Elina Leinonen, Jesse Haapoja and Elena Waschinski for practical assistance and help with data collection. We also thank Simon Lolliot (Oxford Centre for the Study of Intergroup Conflict, University of Oxford) for useful insights related to previous research on secondary transfer effects. 


\section{References}

Allport, G., W. (1954). The nature of prejudice. Reading: Addison-Wesley.

Arbuckle, J. L. (2010). Amos (version 18). Chicago, IL: SPSS Inc.

Barlow, F. K., Louis, W. R., \& Terry, D. J. (2010). Minority report: Social identity, cognitions of rejection and intergroup anxiety predicting prejudice from one racially marginalized group towards another. European Journal of Social Psychology, 40, 805-818. DOI: 10.1002/ejsp.651

Barlow, F. K., Paolini, S., Pedersen, A., Hornsey, M. J., Radke, H. R., Harwood, J., Rubin, M., \& Sibley, C. G. (2012). The contact caveat: Negative contact predicts increased prejudice more than positive contact predicts reduced prejudice. Personality and Social Psychology Bulletin, 38, 1629-1643. DOI: $10.1177 / 0146167212457953$

Bikmen, N. (2011). Asymmetrical effects of contact between minority groups: Asian and black students in a small college. Cultural Diversity and Ethnic Minority Psychology, 17, 186-194. DOI: 10.1037/a0023230

Binder, J., Zagefka, H., Brown, R., Funke, F., Kessler, T., Mummendey, A., ... \& Leyens, J. P. (2009). Does contact reduce prejudice or does prejudice reduce contact? A longitudinal test of the contact hypothesis among majority and minority groups in three European countries. Journal of Personality and Social Psychology, 96, 843. DOI: $10.1037 / \mathrm{a} 0013470$

Berry, J., Phinney, J., Sam, D., \& Vedder, P. (2006). Immigrant youth in cultural transition: Acculturation, identity, and adaptation across national contexts. Mahwah, NJ: Erlbaum. 
Bowman, N. A., \& Griffin, T. M. (2012). Secondary transfer effects of interracial contact: The moderating role of social status. Cultural Diversity and Ethnic Minority Psychology, 18, 35. DOI: 10.1037/a0026745

Brown, R., \& Hewstone, M. (2005). An integrative theory of intergroup contact. Advances in Experimental Social Psychology, 37, 255-343. DOI: $10.1016 / \mathrm{S} 0065-2601(05) 37005-5$

Davydova, O., \& Heikkinen, K. (2004). Produced Finnishness in the context of remigration. In V. Puuronen, A. Häkkinen, T. Pylkkänen, T. Sandlund, \& R. Toivanen (Eds.), New challenges for the welfare society (pp.176-192). University of Joensuu: Publications of Karelian Institute.

Eller, A., \& Abrams, D. (2004). Come together: Longitudinal comparisons of Pettigrew's reformulated contact model and the common ingroup identity model in Anglo-French and Mexican-American contexts. European Journal of Social Psychology, 34, 229-256. DOI: 10.1002/ejsp.194

Esses, V. M., Jackson, L. M., Dovidio, J. F., \& Hodson, G. (2005). Instrumental relations among groups: Group competition, conflict, and prejudice. In J. F. Dovidio, P. Glick, \& L. A. Rudman (Eds.), On the nature of prejudice. Fifty years after Allport (pp. 227-243). Malden: Blackwell.

González, K. V., Verkuyten, M., Weesie, J., \& Poppe, E. (2008). Prejudice towards muslims in the Netherlands: Testing integrated threat theory. British Journal of Social Psychology, 47, 667-685. DOI: 10.1348/014466608X284443

Harwood, J., Paolini, S., Joyce, N., Rubin, M., \& Arroyo, A. (2011). Secondary transfer effects from imagined contact: Group similarity affects the generalization 
gradient. British Journal of Social Psychology, 50, 180-189. DOI:

$10.1348 / 014466610 X 524263$

Hayes, A. F. (2009). Beyond Baron and Kenny: Statistical mediation analysis in the new millenium. Communication Monographs, 76, 408-420.

Fredrickson, B. L. (2001). The role of positive emotions in positive psychology: The broaden-and-build theory of positive emotions. American Psychologist, 56(3), 218-226. DOI: 10.1037//0003.066X.56.3.218

Islam, M. R., \& Hewstone, M. (1993). Dimensions of contact as predictors of intergroup anxiety, perceived out-group variability, and out-group attitude: An integrative model. Personality and Social Psychology Bulletin, 19(6), 700-710.

Jaakkola, M. (2005). Suomalaisten suhtautuminen maahanmuuttajiin vuosina 1987-2003 [The attitudes of Finns toward immigrants in 1987-2003]. Helsinki: Työministeriö.

Jasinskaja-Lahti, I., Liebkind, K., \& Perhoniemi, R. (2006). Perceived discrimination and psychological well-being: A victim study of different immigrant groups. Journal of Community and Applied Social Psychology, 16, 267-284. DOI: 10.1002/casp.865

Jasinskaja-Lahti, I., Mähönen, T. A., \& Liebkind, K. (2011). Ingroup norms, intergroup contact and intergroup anxiety as predictors of the outgroup attitudes of majority and minority youth. International Journal of Intercultural Relations, 35, 346355. DOI: 10.1016/j.ijintrel.2010.06.001.

Jasinskaja-Lahti, I., Mähönen, T. A., \& Liebkind, K. (2012). Identity and attitudinal reactions to perceptions of inter-group interactions among ethnic migrants: A 
longitudinal study. British Journal of Social Psychology, 51, 312-329. DOI:

10.1111/j.2044-8309.2011.02059.x.

Jonas, K. (2009). Interventions enhancing intergroup tolerance. In S. Otten, K. Sassenberg, \& T. Kessler (Eds.), Intergroup relations. The role of motivation and emotion (pp. 284-304). Hove: Psychology Press.

Lebedeva, N., \& Tatarko, А. (2005). Этническая идентичность, статус группы и тип расселения как факторы межгрупповой интолерантности (Ethnic intolerance, group status and population density as factors related to intergroup intolerance). Психологический журнал (Journal of Psychology), 26, 51-64.

Liebkind, K., Mannila, S., Jasinskaja-Lahti, I., Jaakkola, M., Kyntäjä, E., \& Reuter, A. (2004). Venäläinen, virolainen, suomalainen. Kolmen maahanmuuttajaryhmän kotoutuminen Suomeen. [Russian, Estonian, Finnish. The adaptation of three immigrant groups to Finland.] Helsinki: Gaudeamus.

Lolliot, S. (2013). The secondary transfer effect of contact (Unpublished doctoral dissertation). Oxford University, Oxford.

Lolliot, S., Schmid, K., Hewstone, M., Al Ramiah, A., Tausch, N., \& Swart, H. (2013). Generalized effects of intergroup contact. The secondary transfer effect. In G. Hodson \& M. Hewstone (Eds.), Advances in intergroup contact (pp. 81-112). Hove: Psychology Press.

Mähönen, T. A., Ihalainen, K., \& Jasinskaja-Lahti, I. (2013). Specifying the contact hypothesis in a minority-minority context: A social identity perspective. Zeitschrift für Psychologie, 221(4), 223-231. DOI: 10.1027/2151-2604/a000152 
Mähönen, T. A., \& Jasinskaja-Lahti, I. (2012). Anticipated and perceived intergroup relations as predictors of immigrants' identification patterns: A follow-up study. European Psychologist, 17(2), 120. DOI: 10.1027/1016-9040/a000114

Mähönen, T. A., Jasinskaja-Lahti, I., Liebkind, K., \& Finell, E. (2011). Perceived importance of contact revisited: Anticipated consequences of intergroup contact for the ingroup as predictors of the explicit and implicit ethnic attitudes of youth. Group Processes \& Intergroup Relations, 14, 19-30. DOI:

$10.1177 / 1368430210378300$

Pettigrew, T. F. (1998). Intergroup contact theory. Annual Review of Psychology, 49(1), 65-85.

Pettigrew, T. F. (2009). Secondary transfer effect of contact: Do intergroup contact effects spread to noncontacted outgroups? Social Psychology, 40, 55-65. DOI: $10.1027 / 1864-9335.40 .2 .55$

Pettigrew, T. F., \& Tropp, L. R. (2006). A meta-analytic test of intergroup contact theory. Journal of Personality and Social Psychology, 90(5), 751-783. DOI: $10.1037 / 0022-3514.90 .5 .751$

Pettigrew, T. F., Tropp, L. R., Wagner, U., \& Christ, O. (2011). Recent advances in intergroup contact theory. International Journal of Intercultural Relations, 35, 271-280. DOI: 10.1016/j.ijintrel.2011.03.001

Phinney, J. S., Ferguson, D. L., \& Tate, J. D. (1997). Intergroup attitudes among ethnic minority adolescents: A causal model. Child Development, 68, 955-969.

Preacher, K. J., \& Hayes, A. F. (2008). Asymptotic and resampling strategies for assessing and comparing indirect effects in multiple mediator models. Behavior Research Methods, 40, 879-891. 
Riek, B. M., Mania, E. W., \& Gaertner, S. L. (2006). Intergroup threat and outgroup attitudes: A meta-analytic review. Personality and Social Psychology Review, 10(4), 336-353. DOI: 10.1207/s15327957pspr1004_4.

Schmitt, M. T., \& Branscombe, N. R. (2002). The meaning and consequences of perceived discrimination in disadvantaged and privileged social groups. European Review of Social Psychology, 12, 167-199. DOI: 10.1080/14792772143000058.

Schwartz, S. (2007). Universalism, values, and the inclusiveness of our moral universe. Journal of Cross-Cultural Psychology, 38, 711-728. DOI: $10.1177 / 0022022107308992$

Statistics Finland (2013). Population structure of Finland. Retrieved 1.5.2013 from http://tilastokeskus.fi/til/vaerak/2012/vaerak_2012_2013-03-22_tie_001_fi.html.

Stephan, W. G., Boniecki, K. A., Ybarra, O., Bettencourt, A., Ervin, K. S., Jackson, L. A., McNatt, P. S., \& Renfro, C. L. (2002). The role of threats in the racial attitudes of Blacks and Whites. Personality and Social Psychology Bulletin, 28(9), $1242-1254$

Stephan, W. G., Diaz-Loving, R., \& Duran, A. (2000). Integrated threat theory and intercultural attitudes: Mexico and the United States. Journal of Cross-Cultural Psychology, 31, 240-249. DOI: 10.1177/0022022100031002006

Stephan, W. G., Renfro, C. L., \& Davis, M. D. (2008). The role of threat in intergroup relations. In U. Wagner, L. R. Tropp, G. Finchilescu, C. Tredoux (Eds.), Improving Intergroup Relations: Building on the legacy of Thomas F. Pettigrew (pp. 55-72). Malden: Blackwell Publishing. 
Stephan, W. G., \& Stephan, C., W. (2000). An integrated threat theory of prejudice. In S. Oskamp (Ed.), Reducing prejudice and discrimination (pp. 23-45). Mahwah: Lawrence Erlbaum Associates.

Swart, H. (2008). Affective mediators of intergroup contact: Cross-sectional and longitudinal analyses in South Africa (Unpublished doctoral dissertation). Oxford University, Oxford.

Tausch, N., Hewstone, M., Kenworthy, J. B., Psaltis, C., Schmid, K., Popan, J. R., Cairns, E., \& Hughes, J. (2010). Secondary transfer effects of intergroup contact: Alternative accounts and underlying processes. Journal of Personality and Social Psychology, 99, 282-302. DOI: 10.1037/a0018553

Tausch, N., Tam, T., Hewstone, M., Kenworthy, J., \& Cairns, E. (2007). Individual-level and group-level mediators of contact effects in Northern Ireland: The moderating role of social identification. British Journal of Social Psychology, 46, 541556. DOI: 10.1348/014466606X155150

Tropp, L. R., \& Bianchi, R. A. (2006). Valuing diversity and interest in intergroup contact. Journal of Social Issues, 533-551. DOI: 10.1111/j.15404560.2006.00472.x

Tropp, L. R., \& Mallett, R. K. (2011). Moving beyond prejudice reduction: Pathways to positive intergroup relations. Washington, DC: American Psychological Association.

Tropp, L. R., \& Pettigrew, T. F. (2005). Relationships between intergroup contact and prejudice among minority and majority status groups. Psychological Science, 16, 951-957. DOI: 10.1111/j.1467-9280.2005.01643.x 
Van Laar, C., Levin, S., Sinclair, S., \& Sidanius, J. (2005). The effect of university roommate contact on ethnic attitudes and behaviour. Journal of Experimental Social Psychology, 41, 329-345. DOI: 10.1016/j.jesp.2004.08.002

Varjonen, S., Arnold, L., \& Jasinskaja-Lahti, I. (2013). “We're Finns here, and Russians there": A longitudinal study on ethnic identity constructions in the context of ethnic migration. Discourse \& Society, 24(1), 110-134. DOI:

$10.1177 / 0957926512463632$

Vezzali, L., \& Giovannini, D. (2012). Secondary transfer effect of intergroup contact: The role of intergroup attitudes, intergroup anxiety and perspective taking. Journal of Community \& Applied Social Psychology, 22, 125-144. DOI:

10.1002/casp.1103 